\title{
Assessment of productivity in different thermal working environments
}

\author{
Natalia Krawczyk $^{1^{*}}$ \\ ${ }^{1}$ Faculty of Environmental, Geomatic and Energy Engineering, Kielce University of Technology, \\ Poland
}

\begin{abstract}
In the paper the assessment of subjective productivity is presented as a function of indoor environment parameters on the example of students situated in the intelligent building. The volunteers in several different rooms (of various air temperature, humidity and $\mathrm{CO}_{2}$ concentration) filled in the questionnaires and assessed their current productivity. It might be related to both the educational performance and office work of low intensity. The physical parameters were measured with the microclimate high accuracy meter. The data obtained during the measurements of the indoor air parameters were compared with the subjective assessments of the volunteers and conclusions were drawn as to the impact of the working environment on the productivity of room users. The gathered experimental material might be useful for the building managers, so that proper indoor conditions within buildings might be applied that maximize productivity and working performance.
\end{abstract}

\section{Introduction}

The thermal environment is one of the main elements affecting the comfort of users staying indoors. We spend most of our time indoors. The concept of thermal comfort is understood as a state in which a person is satisfied with the prevailing thermal conditions. It does not feel cold or too warm. Providing thermal comfort has a significant impact on work efficiency. Therefore, the concept of thermal comfort is becoming more and more common. When working or learning in closed rooms, we want to feel comfortable in them. Temperature has the greatest influence on thermal comfort. Relative humidity and $\mathrm{CO}_{2}$ also influence the determination of thermal comfort. If the appropriate climatic conditions are not ensured, we are less efficient, we feel tired, and as a consequence, our efficiency of activities decreases. If it is too warm in the building, and hence the users do not feel thermal comfort, it means that we are wasting energy. Failure to ensure appropriate thermal conditions also affects human health and safety in the room. Given the lifestyle change caused by the coronavirus (Covid-19) pandemic, most users work remotely. Thanks to the right thermal conditions, we are more productive and feel good indoors. Human productivity includes actual labor productivity as well as productivity symptoms. Actual

\footnotetext{
*Corresponding author: nkrawczyk@tu.kielce.pl
} 
productivity relates primarily to the result attainable by a person who is studying or working.

Lipczyńska et al. [1] conducted research in terms of productivity and efficiency. The test consisted of conducting tests in three temperature conditions: $23{ }^{\circ} \mathrm{C}, 26{ }^{\circ} \mathrm{C}$ and 27 ${ }^{\circ} \mathrm{C}$. The study involved 14 participants who felt drowsy at the highest air temperature. The article uses a scale from "not productive" to "very productive". They concluded that the subjects' productivity increased as the thermal conditions improved. The more comfortable they feel, the more concentration they are. Akimoto et al. [2] conducted research comparing thermal comfort with productivity. The authors examined parameters such as air temperature, radiation temperature, air flow velocity and relative humidity. The study on the feeling of fatigue showed that the participants were most likely to feel sleepy and it was mainly dependent on the type of work. The author [3] confirms that the parameters of thermal comfort affect the users staying in the rooms. Similar results were obtained by Yingdong et al. [4]. They confirmed that human productivity is better when the building is under neutral conditions. They compared participants' productivity in rooms with and without fans. They found that labor productivity was reduced in fanless rooms. The authors [5] conducted research on productivity in office buildings, in which they collected 9794 questionnaires. They observed that working hours, proximity to windows, and location of the workplace had the greatest impact on the decline in productivity. If the employee's workplace is close to the window, it has a positive effect on work efficiency. Kaushik et al. [6] discussed eight dependencies that have a direct impact on productivity and thermal comfort. They analysed individual relationships, including the influence of $\mathrm{CO}_{2}$, relative humidity, volatile organic compounds and air temperature. According to the study [6], relative humidity has a stronger and direct impact on productivity and thermal comfort than carbon dioxide. Relative humidity has a positive effect of up to $55 \%$ on the productivity and thermal comfort of users. Kumar et al. [7] analysed the adaptation study of thermal comfort. They found that study participants felt comfortable in a wider range of temperatures. Majewski et al. [8,9] conducted research in an intelligent building and observed significant differences between the actual values of thermal comfort and the forecast ones. The other papers of these authors and others $[10,11]$ focused on tests in intelligent buildings confirm these findings. Biyik et al. [12] carried out research on energy storage from photovoltaic panels. Thanks to renewable energy sources, we can use it later and maintain thermal comfort in a given building. Kükrer et al. [13] proposed a party model with the value of temperature and humidity. This allowed to reduce energy costs and improve thermal comfort in the school building, which will have an impact on the students' productivity. On the other hand, the author [14] conducted research on the modernization of buildings in order to improve thermal comfort, reduce costs and increase productivity.

Thermal comfort has a significant impact on the productivity of users, however this issue has not been completely understood and fully described. The article presents a study in which students completed questionnaires and assessed their current productivity. The data obtained from the questionnaires and measurements of air parameters were compared in terms of user productivity.

\section{Material and method}

The research was carried out in the intelligent building "Energis" of the Kielce University of Technology in 2020-2021. The presented building has mechanical ventilation. The building is equipped with solar collectors, photovoltaic cells and heat pumps that use solar energy to generate electricity to illuminate the building and heat water. Photovoltaic panels and solar collectors have been placed on the roof of the building, making the building self- 
sufficient. Below is a photo of the "Energis" building of the Kielce University of Technology from the Western side.

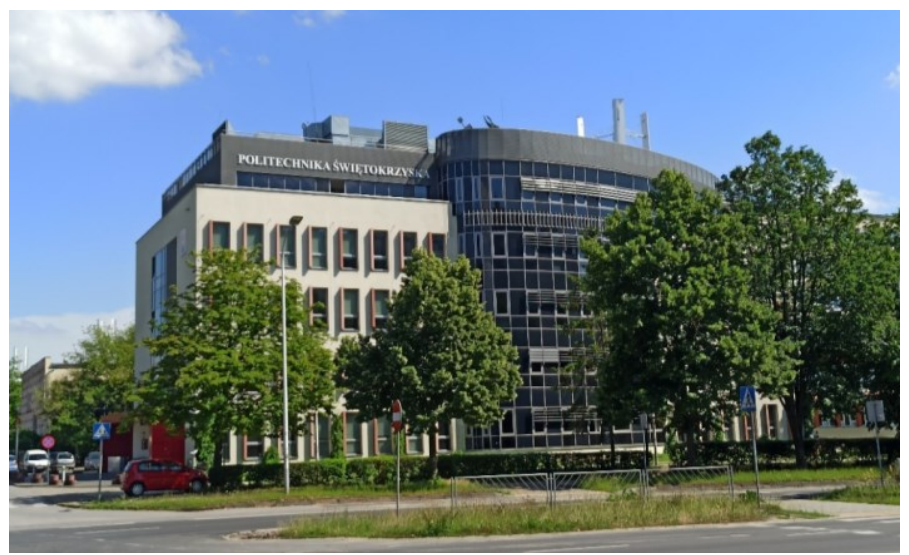

Fig. 1. Photo of the "Energis" building.

The presented "Energis" building was designed to ensure adequate air parameters for people staying in it. The air-conditioning and heating systems in it should ensure appropriate parameters in the room. The research consisted in the simultaneous registration of the parameters of the microclimate of the room in which the measurements and questionnaire surveys are carried out at a given moment. For microclimate studies, a Testo 400 meter with probes was used, which enables precise measurements of air temperature and humidity, black ball temperature, carbon dioxide concentration, air velocity and light intensity. The device is placed in the central part of the room on a tripod, and the recorded values are saved in the meter's memory for later analysis. Figure 2 below shows the Testo 400 gauge that was used for the tests.

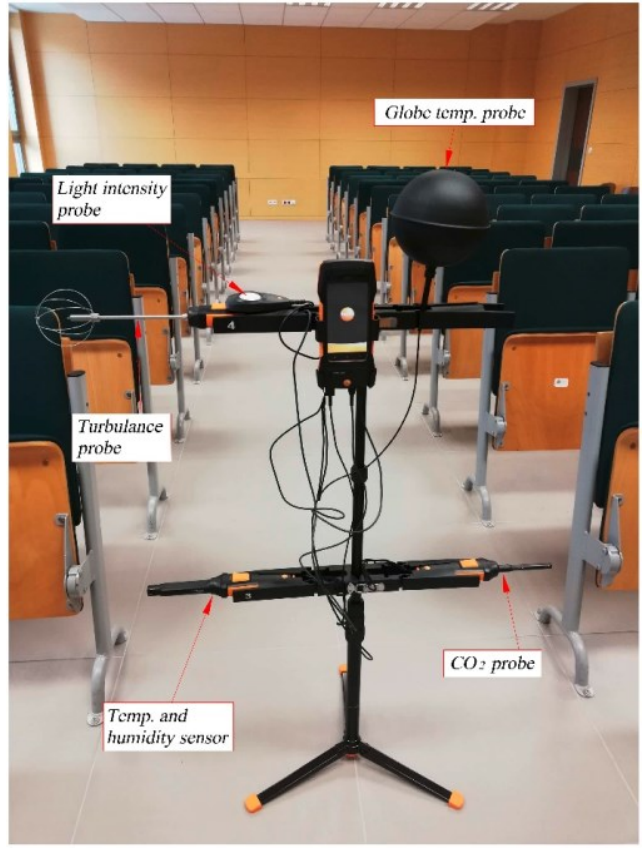

Fig. 2. Testo 400 microclimate measuring device. 
The parameters were read from the meter after 15 minutes of stabilization of the measurements. At that time, the volunteers filled out questionnaires. The values recorded by the meter in the given intervals were averaged. The graph of temperature and $\mathrm{CO}_{2}$ changes over time is presented below.

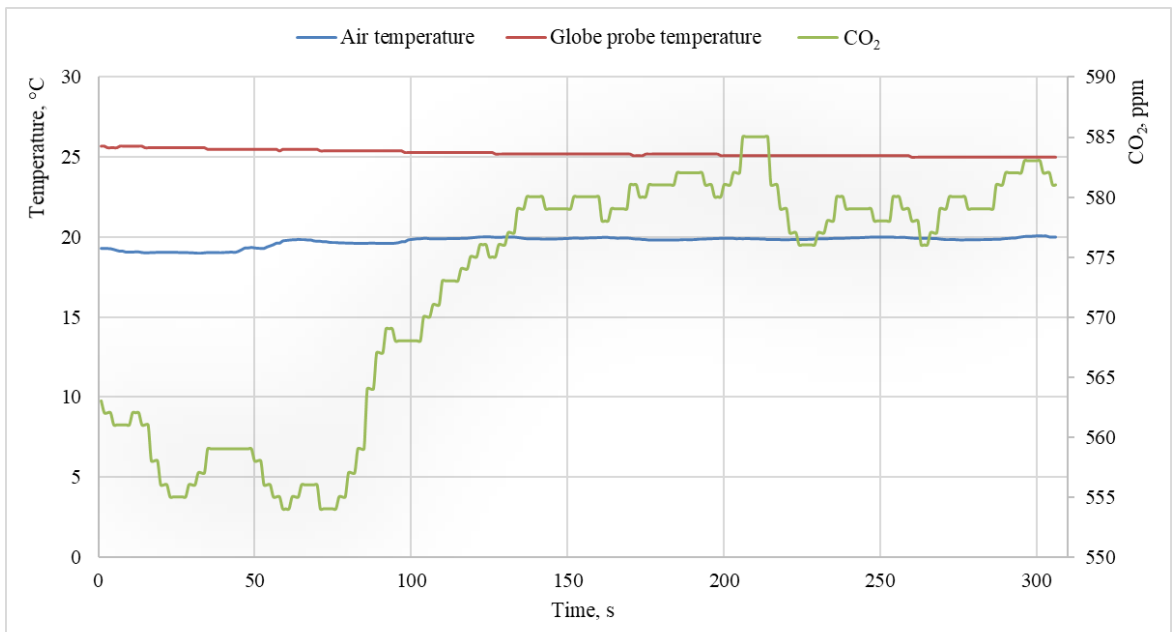

Fig. 3. Graph of temperatures and carbon dioxide over time.

It can be seen from the graph that the air temperature and the black sphere temperature remained constant throughout the test period. In contrast, carbon dioxide fluctuates significantly. From the moment the meter was turned on, its value increased significantly until the end of the test. During the measurement, the volunteers completed questionnaires. An anonymous questionnaire filled in by each volunteer includes questions regarding, among others, current thermal sensations, preferences in terms of possible changes in air temperature, assessment of air humidity, light level, own productivity, subjective indoor air quality. In addition, at the end of the questionnaire, a certificate was placed, which contains information about age, gender, height and weight, as well as the current state of health and clothing worn at the moment. The thermal resistance of the office chair was added to the value of thermal resistance for clothes, which is 0.1 clo. The next figure shows the volunteers filling out the questionnaires.

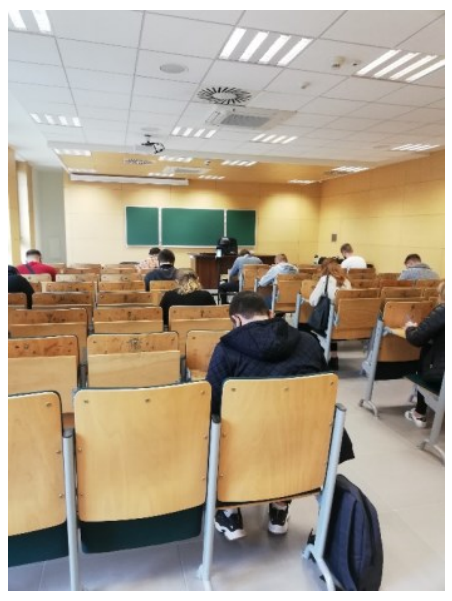

Fig. 4. Participants completing the questionnaires during the microclimate test. 
People aged 18 to 28 and one man aged 41 participated in the study. The survey also included a question about health. When someone answered "yes", such a questionnaire was rejected due to the thermal feelings of the sick, which are not reliable.

\section{Results and discussion}

The research was carried out in the intelligent building "Energis" of the Kielce University of Technology, in which 12 measurements were made (in 12 rooms with different groups of people). A total of 156 people took part in the research, including 56 women and 100 men. In the tested rooms, there is mechanical ventilation with a panel controlling air parameters, which was not used during the tests. Air temperature ranged between $19.3{ }^{\circ} \mathrm{C}$ and $25.2{ }^{\circ} \mathrm{C}$. The figure below presents the frequency of the answers given regarding the learning productivity in the building under study.

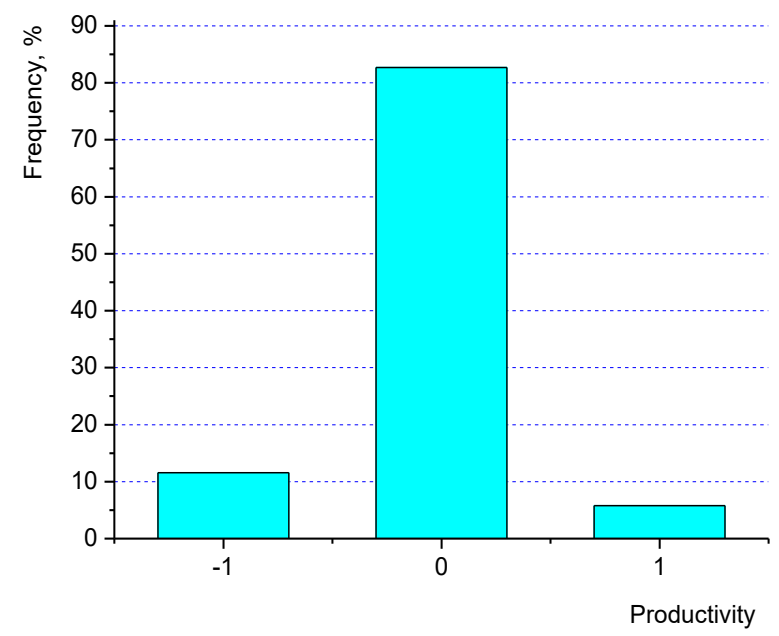

Fig. 5. The frequency of responses given by respondents regarding productivity: -1 - Weak (worse than usual), 0 - Normal (the same as usual), 1 - High (better than usual).

It can be seen in the presented chart that the most frequently given answer was "Normal" and it amounted to $82.69 \%$ of all the answers. The second answer given was "Weak" and it was 11.54, while "High" was the least chosen answer (5.77\%). It is worth noting that the thermal sensations of respondents depend on many factors, including temperature, air velocity, and even clothing. The influence of carbon dioxide should also be included, as shown in the next figure (Fig. 6) - for 12 different rooms, of different air temperature and $\mathrm{CO}_{2}$ concentration. The average productivity for each group was calculated as the mean value of the peoples' responses in the questionnaires. 


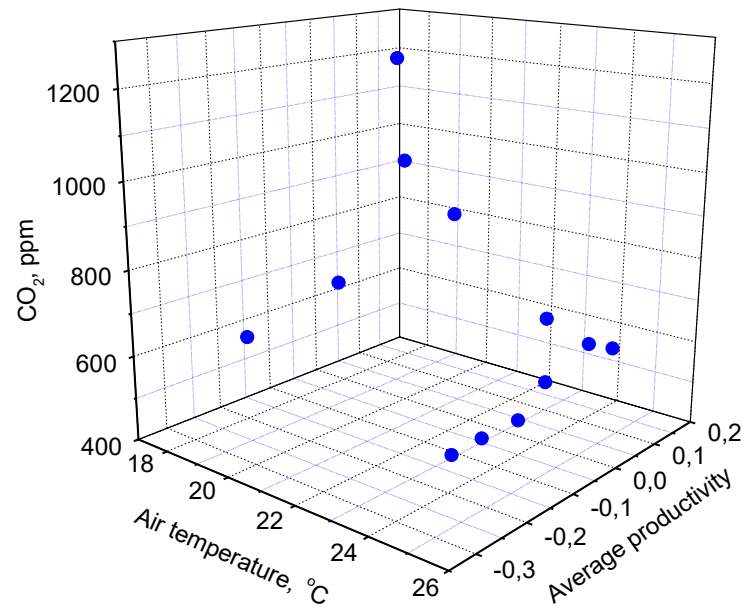

Fig. 6. Graph of air temperature preferences and average productivity by respondents.

The research on the ability to learn new knowledge has shown that both temperature and carbon dioxide concentration might not have as significant impact as expected. It might be linked with a relatively low level of $\mathrm{CO}_{2}$ concentration (not exceeding $1200 \mathrm{ppm}$ ). However, the students also indicated in the questionnaires how well they feel in the room (“+2": very fine, “+1" fine", "0": neutral, “-1": "bad" and "-2": "very bad"). The average value of their well-being for each group of students has shown some relationship with the productivity as presented in Figure 7.

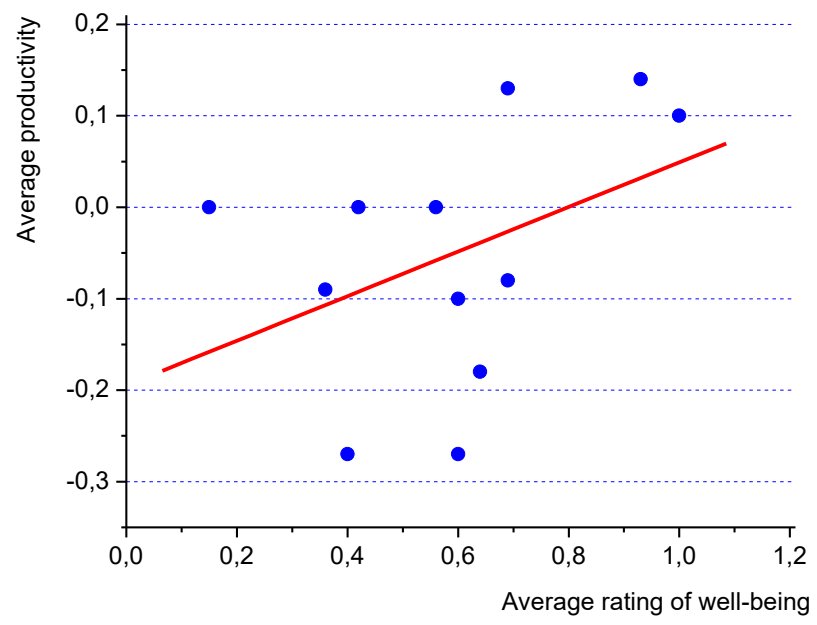

Fig. 7. Graph of average productivity and average rating of well-being.

The figure above shows the average values for the productivity of the rooms tested and the overall assessment. The chart shows that people who feel better indoors have better productivity. This relationship is not very strong because there is a small value of the matching factor $\mathrm{R}^{2}$, which is 0.1693 , but the trend might be indicated. The best solution will be to analyse a larger research group or at a different age. This will allow you to check whether $\mathrm{CO}_{2}$ or other indoor parameters affects the ability to absorb knowledge in the room. 


\section{Conclusions}

Research carried out in the intelligent building "Energis" of the Kielce University of Technology has shown that the productivity is affected, at least to some extent, by the subjective well-being of the people. The intelligent building HVAC systems kept the $\mathrm{CO}_{2}$ value within the normal range, so students did not experience any problems and their productivity might not have been changed. It is certain that providing volunteers with a comfortable thermal environment has an impact on their health and productivity. This is essential for a better learning capacity in educational buildings.

Such studies can be useful for building managers to apply the appropriate indoor conditions. It is recommended that internal conditions take into account productivity and work efficiency. The topic requires further research to check and compare whether $\mathrm{CO}_{2}$ and temperature values affect the productivity of knowledge acquisition. It is worth doing research also for a different age group. A better internal environment and its quality can result in a significant improvement in user productivity.

\section{References}

1. A. Lipczyńska, S. Schiavon, L.T. Graham, BaE 135, 202-212 (2018) https://doi.org/10.1016/j.buildenv.2018.03.013

2. T. Akimoto, S. Tanabe, T. Yanai, M. Sasaki, BaE 45, 45-50 (2010) https://doi.org/10.1016/j.buildenv.2009.06.022

3. W.G.B. Council, Health, Wellbeing \& Productivity in Offices, World Green Building Council (2014)

4. Y. He, W. Chen, Z. Wang, H. Zhang, E\&B 194, 140-162 (2019) https://doi.org/10.1016/j.enbuild.2019.04.015

5. O. Göçer, Ch. Candido, L. Thomas, K. Göçer, Buildings 9, 199 (2019) https://doi.org/10.3390/buildings9090199

6. A. Kaushik, M. Arif, P. Tumula, O.J. Ebohon, BaE 180 (2020) 107021 https://doi.org/10.1016/j.buildenv.2020.107021

7. S. Kumar, A. Mathur, M.K. Singh, K.B. Rana, BaE $197 \quad$ (2021) 107874 https://doi.org/10.1016/j.buildenv.2021.107874

8. G. Majewski, Ł.J. Orman, M. Telejko, N. Radek, J. Pietraszek, A. Dudek., Energies, 13 (8), 1973 (2020) https://doi.org/10.3390/en13081973

9. G. Majewski, M. Telejko, Ł.J. Orman, Proc. of Conf. on Interdisciplinatry Problems in Environmental Protection and Engineering (EKO-DOK), Poland, E3S Web of Conferences, 17, 00056 (2017) https://doi.org/10.1051/e3sconf/20171700056

10. Krawczyk N., E3S Web of Conferences 246, 15003, Tallinn, Estonia (2021) https://doi.org/10.1051/e3sconf/202124615003

11. L. Dębska, J. Krakowiak, Proc of Int. Conf. ICSF, E3S Web of Conferences 280, 04011 (2021) https://doi.org/10.1051/e3sconf/202128004011

12. E. Biyik, A. Kahraman, Journal of Building Engineering 25 (2019) https://doi.org/10.1016/j.jobe.2019.100826

13. E. Kükrer, N. Eskin, Journal of Building Engineering 44 (2021) 102697 https://doi.org/10.1016/j.jobe.2021.102697

14. Ö. Duran, K.J.Lomas, Journal of Building Engineering $42 \quad$ (2021) 102746 https://doi.org/10.1016/j.jobe.2021.102746 